\title{
Resposta sorológica aos herpesvirus bovino tipos 1 e 5 e vírus da diarreia viral bovina induzida por vacinas comerciais
}

\author{
Serological response to bovine herpesvírus 1 and 5 and \\ bovine viral diarrea virus induced by comercial vaccines
}

\author{
Deniz Anziliero ${ }^{\mathrm{I}}$ Mathias Martins ${ }^{\mathrm{I}}$ Marcelo Weiss $^{\mathrm{I}}$ Francielle Liz Monteiro $^{\mathrm{I}}$ \\ Cássio Frustenal Ataide ${ }^{\mathrm{I}}$ Rudi Weiblen ${ }^{\mathrm{I}}{\text { Eduardo Furtado } \text { Flores }^{\mathrm{I}}}^{*}$
}

\section{RESUMO}

Este trabalho avaliou a imunogenicidade de vacinas para os herpesvírus bovino 1 e 5 (BoHV-1, BoHV-5) e vírus da diarreia viral bovina 1 e 2 (BVDV-1, BVDV-2), disponíveis no mercado brasileiro. Para isso, novilhos de raças de corte foram alocados em grupos de 10-12 animais e vacinados duas vezes, com intervalo de 30 dias, com cada uma das oito vacinas disponíveis. Amostras de soro coletadas 30 dias após a segunda dose foram submetidas ao teste de virusneutralização (VNT), frente a cepas de BoHV-1, BoHV-5, BVDV-1 e BVDV-2. Com exceção de duas vacinas que induziram soroconversão em $8 / 10$ e 9/10 dos animais, as demais induziram anticorpos neutralizantes contra o $\mathrm{BoHV}-1$ em todos os animais vacinados (títulos médios geométricos [GMTs] entre 1,7 e 4,8). Quatro vacina s induziram anticorpos reagentes com o BoHV-5 em todos os animais (GMTs de 1,0 a 4,2), enquanto três vacinas induziram soroconversão parcial em 5/10, 6/10 e 7/10 animais. Apenas uma vacina induziu resposta sorológica detectável frente ao BVDV-1 em todos os animais vacinados $(G M T=6,7)$. Soroconversão parcial ao BVDV-1 foi detectada em quatro grupos vacinais (6/10, GMT 4,0 6/10, GMT 5,6 e 4/10, GMT 1,8). Uma vacina induziu resposta em apenas um animal (título de 40) e três vacinas não induziram anticorpos detectáveis contra o BVDV-1 em nenhum animal. Atividade neutralizante frente ao $B V D V-2$ foi detectada apenas em três grupos vacinais, e parcialmente (10/10, GMT 6,5; 5/10, GMT 1,6 e 2/10, GMT 1,0). Cinco vacinas não induziram atividade neutralizante detectável frente ao $B V D V-2 \mathrm{em}$ nenhum dos animais imunizados. Esses resultados demonstram que o componente BoHV-1 da maioria das vacinas comerciais possui imunogenicidade adequada. No entanto, o componente BVDV da grande maioria das vacinas não induz resposta neutralizante consistente frente ao BVDV-1 e, principalmente, frente ao BVDV-2. Fica evidente que as estratégias de formulação elou produção de vacinas, principalmente com relação ao BVDV, devem ser urgentemente revistas.

Palavras-chave: doenças reprodutivas, imunogenicidade, resposta vacinal, sorologia, BVDV, IBR.

\section{ABSTRACT}

This study evaluated the immunogenicity of vaccines for bovine herpesvirus 1 and $5(\mathrm{BoHV}-1 / 5)$ and viral diarrhea virus 1 and $2(B V D V-1 / 2)$ available in the Brazilian market. Calves were divided into groups (10-12), vaccinated twice with a 30 days interval. Samples collected 30 days after the second dose were submitted to virus neutralization test against BoHV-1, BoHV-5, BVDV-1 and $B V D V-2$. With the exception of two vaccines that induced seroconversion in $8 / 10$ and $9 / 10$ of the animals, the other induced antibodies against BoHV-1 in all vaccinated animals (geometric mean titers [GMTs] 1.7 and 4.8) and four induced antibodies against BoHV-5 in all animals (GMTs 1.0 to 4.2), whereas three vaccines induced partial seroconversion (5/10, 6/10 and 7/10 animals). Only one vaccine induced antibody response to BVDV-1 in all vaccinated animals $(G M T=6.7)$. Partial seroconversion to BVDV-1 was detected in four vaccine (6/10, GMT 4.0; 6/10, GMT 5.6 and 4/10, GMT 1.8). A vaccine induced response in only one animal and three vaccines did not induce antibodies against BVDV-1 in any animal. Antibodies to BVDV-2 were detected only in three vaccine groups, and partly (10/10, GMT 6.5; 5/10, GMT 1.6 and 2/10, GMT 1.0). Five vaccines did not induce antibodies to $B V D V-2$ in any of the animals. Results demonstrate that the BoHV-1 component of commercial vaccines seems to have acceptable immunogenicity. However, the BVDV component of most vaccines does not induce consistent response against BVDV-1, especially, to BVDV-2. It is evident that strategies for production of vaccines, particularly to $B V D V$ must be urgently revised.

Key words: reproductive diseases, immunogenicity, vaccine response, serology, $B V D V, I B R$.

\section{INTRODUÇÃO}

Os herpesvírus bovinos tipos 1 (BoHV-1) e 5 (BoHV-5) e o vírus da diarreia viral bovina (BVDV)

\footnotetext{
IPrograma de Pós-graduação em Medicina Veterinária, Setor de Virologia, Departamento de Medicina Veterinária Preventiva, Universidade Federal de Santa Maria (UFSM), 97105-900, Santa Maria, RS, Brasil. E-mail: eduardofurtadoflores@gmail.com.*Autor para correspondência.
} 
estão entre os patógenos mais importantes de bovinos e causam importantes perdas à bovinocultura em todo o mundo. O BoHV-1 está associado com doença respiratória (rinotraqueíte infecciosa bovina, IBR), genital (vulvovaginite [IPV] nas fêmeas e balanopostite [IPB] em touros), infertilidade e abortos (ENGELS \& ACKERMANN, 1996) e possui distribuição virtualmente mundial (ACKERMAN \& ENGELS, 2006). O BoHV-5 é o agente de meningoencefalite de curso geralmente fatal que acomete principalmente animais jovens, doença de ocorrência endêmica em vários países da América do Sul, incluindo o Brasil (SILVA et al., 2007). O BoHV-1 e BoHV-5 são antigenicamente relacionados, o que pode representar um problema para o diagnóstico sorológico diferencial entre eles. Entretanto, a forte reatividade entre os herpesvírus bovinos pode ser considerada como um fator importante para proteção cruzada em resposta à vacinação (ANZILIERO et al., 2011).

O BVDV possui distribuição mundial e está associado com uma grande variedade de manifestações clínicas, que incluem doença respiratória, gastroentérica, doença hemorrágica, imunossupressão e distúrbios reprodutivos, entre outras (RIDPATH et al., 1994). Os isolados de BVDV apresentam uma grande variabilidade antigênica, e podem ser divididos em dois grupos genética e antigenicamente distintos, sendo identificados como duas espécies virais: BVDV-1 e BVDV-2 (RIDPATH et al., 1994), sendo, posteriormente, divididos oficialmente em duas espécies distintas pelo Comitê Internacional de Taxonomia de Viroses (ICTV). A baixa reatividade sorológica entre os isolados e, principalmente, entre os grupos dificulta o diagnóstico e a prevenção por vacinação (BIANCHI et al., 2011).

Vários estudos demonstram que esses agentes estão amplamente distribuídos no rebanho bovino brasileiro, mas a sua real prevalência é desconhecida. Isto se deve, sobretudo, à falta de estudos soroepidemiológicos abrangentes e representativos, assim como o uso crescente da vacinação, cuja resposta sorológica é indistinguível daquela induzida pela infecção natural (FLORES et al., 2000).

A vacinação contra esses agentes no Brasil é voluntária e, embora não seja tão utilizada como em países europeus e norte-americanos, tem aumentado nas últimas décadas. Esse aumento deve-se, em parte, aos crescentes relatos das enfermidades, mas também pela pressão exercida pela indústria de vacinas (Comunicação pessoal).

Várias vacinas para o BoHV-1 e BVDV são atualmente comercializadas no país. Essas vacinas contêm diferentes combinações de antígenos e cepas vacinais e contêm também outros agentes virais e bacterianos incluídos nas formulações (MAPA, 2013). Além da expansão da vacinação e da introdução de novas vacinas no mercado, as últimas décadas têm testemunhado o surgimento e/ ou identificação de novos subtipos ou variantes virais, entre as quais o BVDV-2, e vários subtipos de BVDV-1 e BVDV-2 (BIANCHI et al., 2011). Além disso, alguns pestivírus atípicos têm sido identificados recentemente, principalmente no Brasil (BAUERMANN et al., 2013), aumentando a preocupação sobre a eficácia das vacinas.

Assim, o objetivo do presente trabalho foi avaliar a imunogenicidade das vacinas disponíveis no mercado brasileiro, quantificando-se a resposta sorológica induzida pela vacinação frente a cepas representativas dos quatro agentes.

\section{MATERIAL E MÉTODOS}

Vírus e células

Os procedimentos de amplificação, titulação viral e testes sorológicos foram realizados em células de rim bovino da linhagem MDBK (MadinDarby bovine kidney) livres de pestivírus. As células foram cultivadas em meio essencial mínimo (MEM), suplementado com $10 \%$ de soro equino, $10 \mathrm{U} \mathrm{mL}^{-1} \mathrm{de}$ penicilina e $100 \mathrm{mg} \mathrm{mL}^{-1}$ de estreptomicina. Os vírus utilizados na técnica de vírusneutralização (VNT) foram BoHV-1 (Cooper), BoHV-5 (SV507/99), BVDV-1 (Singer) e BVDV-2 (VS-253).

\section{Animais, vacinas e imunização}

Foram utilizados 87 bovinos de raças mistas, com idade entre oito e doze meses, previamente testados e soronegativos para BoHV-1 e 5 e BVDV-1 e 2 pelo teste de vírusneutralização (VNT) (OIE, 2013). Os animais eram pertencentes a propriedades de pecuária de corte na região central do Rio Grande do Sul. Os animais foram aleatoriamente divididos em grupos de 10 a 12 animais e cada grupo foi imunizado com uma vacina (Tabela 1). A imunização seguiu estritamente as recomendações dos fabricantes: duas aplicações com intervalo de 28-30 dias, pela via intramuscular ou subcutânea. Amostras de soro para a pesquisa de anticorpos foram coletadas nos dias 0 (dia da primeira dose vacinal), 30 (dia da segunda dose) e 60 (30 dias após a segunda dose). Em cada propriedade, quatro animais não vacinados foram mantidos junto com os animais vacinados e serviram de sentinelas para monitorar eventual introdução dos agentes durante o período experimental.

Ciência Rural, v.45, n.1, jan, 2015. 
Tabela 1 - Composição das vacinas comerciais utilizadas no experimento.

\begin{tabular}{|c|c|c|}
\hline Vacina & Composição & Dose e via de aplicação \\
\hline A & Vacina inativada (BoHV-1, BoHV-5, BVDV-1, BVDV-2); adjuvante oleoso & $\begin{array}{l}2 \times 5 \mathrm{~mL} \\
\text { Subcutânea }\end{array}$ \\
\hline $\mathrm{B}$ & Vacina inativada (BoHV-1; BVDV-1; BVDV-2); * & $\begin{array}{l}2 \times 5 \mathrm{~mL} \\
\text { Subcutânea }\end{array}$ \\
\hline $\mathrm{C}$ & Vacina inativada(BHV-1; BVDV-1cp/ncp e BVDV-2 cp); adjuvante hidróxido de alumínio & $\begin{array}{l}2 \times 5 \mathrm{~mL} \\
\text { Subcutânea }\end{array}$ \\
\hline $\mathrm{D}$ & Vacina inativada de BoHV-1, BoHV-5 e BVDV-1 e BVDV-2; adjuvante hidróxido de alumínio & $\begin{array}{l}2 \times 5 \mathrm{~mL} \\
\text { Subcutânea }\end{array}$ \\
\hline $\mathrm{E}$ & Vacina inativada (BoHV-1 e Diarreia BVDV); adjuvante seleniummax & $\begin{array}{l}2 \times 5 \mathrm{~mL} \\
\text { Subcutânea }\end{array}$ \\
\hline $\mathrm{F}$ & Vacina inativada BoHV-1, BVDV-1 e BVDV-2; adjuvante hidróxido de alumínio & $\begin{array}{l}2 \times 5 \mathrm{~mL} \\
\text { Subcutânea }\end{array}$ \\
\hline G & $\begin{array}{l}\text { Vacina quimicamente alterada termossensíveis BoHV-1, BVDV-1, BVDV-2 inativado com } \\
\text { combinação única de adjuvantes, incluindo Amphigen }{ }^{\circledR}\end{array}$ & $\begin{array}{l}2 \times 5 \mathrm{~mL} \\
\text { Subcutânea }\end{array}$ \\
\hline $\mathrm{H}$ & $\begin{array}{l}\text { Vacina viva quimicamente alterada BoHV-1, um diluente composto de uma combinação } \\
\text { inativada de BVDV cp/ncp; Adjuvante Hidróxido de alumínio }\end{array}$ & $\begin{array}{l}2 \times 5 \mathrm{~mL} \\
\text { Intramuscular }\end{array}$ \\
\hline
\end{tabular}

BoHV-1: herpesvírus bovino tipo 1; BoHV-5: herpesvírus bovino tipo 5; BVDV: vírus da diarreia viral bovina; cp: vírus citopático; ncp: vírus não citopático;* sem especificações sobre o adjuvante.

Testes de vírusneutralização (VNT)

A pesquisa de anticorpos neutralizantes foi realizada nas amostras individuais de soro, frente a cepas representativas dos quatro agentes (BoHV-1 Cooper, BoHV-5 SV507/99, BVDV-1 Singer e BVDV-2 VS253), seguindo estritamente o protocolo estabelecido pela OIE (2013). Em placas de 96 cavidades, o soro, previamente submetido à inativação do complemento $\left(56^{\circ} \mathrm{C}\right.$ por $\left.30 \mathrm{~min}\right)$, foi incubado em diluições crescentes, partindo de 1:2 (BoHV) ou 1:5 (BVDV), com aproximadamente 100 a 200 doses infectantes para $50 \%$ dos cultivos celulares $\left(\mathrm{DICC}_{50}\right)$ do respectivo vírus. As placas contendo as misturas soro:vírus foram incubadas por $2 \mathrm{~h}$ a $37^{\circ} \mathrm{C}$, seguido da adição de uma suspensão de células MDBK e incubadas novamente a $37^{\circ} \mathrm{C}$ em atmosfera de $5 \%$ de $\mathrm{CO}_{2}$ A leitura do teste foi realizada após $96 \mathrm{~h}$ de incubação pelo monitoramento do efeito citopático (ECP). O título neutralizante foi considerado a recíproca da maior diluição do soro capaz de neutralizar a replicação viral. Amostras que não apresentaram atividade neutralizante na menor diluição foram consideradas negativas. Os títulos de anticorpos foram transformados em título médio geométrico (GMT) (ANZILIERO et al., 2011).

\section{RESULTADOS}

Os resultados dos testes de VNT realizados com o soro de animais imunizados com as respectivas vacinas (A-H), nos dias 30 e 60 após a dose inicial, estão resumidos na tabela 2. Com exceção das vacinas B e D, que induziram soroconversão em 8/10 e 9/10 animais, respectivamente, as demais vacinas induziram anticorpos neutralizantes, contra o BoHV-1 em todos os animais vacinados, com GMTs que variaram entre 1,7 (vacina C) e 4,8 (vacina $G$ ). A vacina $G$ foi a que induziu títulos neutralizantes $\geq 8$ na maior parcela dos animais (11 de 12 animais), seguido pelas vacinas $\mathrm{H}$ (8/10) e E (7/10). Já a vacina C induziu títulos baixos $(\leq 4)$ em todos os animais.

Quando testados frente ao BoHV-5, todos os animais imunizados com as vacinas $\mathrm{A}, \mathrm{E}, \mathrm{F}, \mathrm{G}$ e $\mathrm{H}$ apresentaram anticorpos neutralizantes (GMTs 1,0 a 4,2), mas três vacinas (B, C e D) induziram soroconversão parcial (em 70\%, 50\% e 60\% dos animais, respectivamente). Novamente, a vacina $G$ foi a que induziu o maior GMT e o maior número de animais com títulos $\geq 8$, contra o BoHV-5. Por outro lado, todos os reagentes à vacina $\mathrm{F}$ apresentaram os títulos neutralizantes mínimos detectáveis pelo teste de VNT (título de 2).

Em resumo, todas as vacinas testadas induziram anticorpos com atividade neutralizante contra o BoHV-1, na totalidade ou na grande maioria dos animais. No entanto, com exceção das vacinas $G$ e $\mathrm{H}$, que induziram títulos moderados a altos em boa parcela dos animais, a maioria dos animais dos outros grupos desenvolveu títulos baixos $(<8)$. A resposta neutralizante frente ao BoHV-5 foi menos consistente 
Tabela 2 - Imunogenicidade de vacinas comerciais para herpesvírus bovino e diarreia viral bovina. Os animais foram vacinados com duas doses das vacinas comerciais, segundo as recomendações do fabricante.

\begin{tabular}{|c|c|c|c|c|c|c|c|c|}
\hline \multirow[t]{2}{*}{ Grupo (n) } & \multicolumn{2}{|c|}{------ BoHV-1 ------- } & \multicolumn{2}{|c|}{-------- BoHV-5 -------- } & \multicolumn{2}{|c|}{-------- BVDV-1 -------- } & \multicolumn{2}{|c|}{---- BVDV-2 ---- } \\
\hline & $\begin{array}{l}\text { Positivos }^{\#} \\
\text { (Títulos) }\end{array}$ & GMT & $\begin{array}{l}\text { Reagentes } \\
\text { (Títulos) }\end{array}$ & GMT & $\begin{array}{l}\text { Reagentes } \\
\text { (Títulos) }\end{array}$ & GMT & $\begin{array}{l}\text { Reagentes } \\
\text { (Títulos) }\end{array}$ & GMT \\
\hline $\mathrm{A}(11)$ & $\begin{array}{l}11^{\#} \\
4 \\
(6) ; 8(3) ; 16 \\
(2)\end{array}$ & 2,6 & $\begin{array}{l}11^{\#} \\
2(5) ; \\
4(3) ; \\
8(3)\end{array}$ & 1,8 & $\begin{array}{l}1^{\#} \\
40(1)\end{array}$ & $\mathrm{Nc}^{*}$ & $0^{\#}$ & - \\
\hline $\mathrm{B}(10)$ & $\begin{array}{l}8^{\#} \\
4(2) ; 8(5) \\
32(1)\end{array}$ & 3,0 & $\begin{array}{l}7^{\#} \\
2(2) ; \\
4(5)\end{array}$ & 1,7 & $\begin{array}{l}6^{\#} \\
80(4), \\
160(2)\end{array}$ & 5,6 & $\begin{array}{l}2^{\#} \\
5(2)\end{array}$ & 1,0 \\
\hline $\mathrm{C}(10)$ & $\begin{array}{l}10^{\#} \\
2(3) ; 4(7)\end{array}$ & 1,7 & $\begin{array}{l}5^{\#} \\
2(3) ; \\
4(2)\end{array}$ & 1,4 & $0^{\#}$ & - & $0^{\#}$ & - \\
\hline $\mathrm{D}(10)$ & $\begin{array}{l}9^{\#} \\
4(4) ; 8(5)\end{array}$ & 2,6 & $\begin{array}{l}6^{\#} \\
4(4) ; 8 \\
(2)\end{array}$ & 2,3 & $0^{\#}$ & - & $0^{\#}$ & - \\
\hline $\mathrm{E}(10)$ & $\begin{array}{l}10^{\#} \\
2(1) ; 4(2) ; \\
8(5) ; 16(2)\end{array}$ & 2,8 & $\begin{array}{l}10^{\#} \\
2(4) ; \\
4(5) ; \\
8(1)\end{array}$ & 1,7 & $\begin{array}{l}4^{\#} \\
5(1), \\
10(3)\end{array}$ & 1,8 & $0^{\#}$ & - \\
\hline $\mathrm{F}(10)$ & $\begin{array}{l}10^{\#} \\
2(3) ; 4(1) ; \\
8(5) ; 16(1)\end{array}$ & 2,6 & $\begin{array}{l}10^{\#} \\
2(10)\end{array}$ & 1,0 & $0^{\#}$ & - & $0^{\#}$ & - \\
\hline $\mathrm{G}(12)$ & $\begin{array}{l}12^{\#} \\
4(1) ; 8(1) ; \\
16(3) ; \\
32(3) ; \\
64(3) ; \\
128(1)\end{array}$ & 4,8 & $\begin{array}{l}12^{\#} \\
2(1) ; \\
8(3) ; \\
16(3) ; \\
32(2) ; \\
64(2) ; \\
128(1)\end{array}$ & 4,2 & $\begin{array}{l}12^{\#} \\
40(1) ; \\
80(3) ; \\
320(5) ; \\
640(1) ; \\
1280(2)\end{array}$ & 6,7 & $\begin{array}{l}12^{\#} \\
20(1) ; \\
40(1) ; \\
160(3) ; \\
320(5) ; \\
1250(1) ; \\
2560(1)\end{array}$ & 6,5 \\
\hline $\mathrm{H}(10)$ & $\begin{array}{l}10 \\
4(2) ; 8(2) \\
16(2) \\
32(4)\end{array}$ & 3,8 & $\begin{array}{l}10^{\#} \\
2(2) ; \\
4(3) ; \\
8(5)\end{array}$ & 2,3 & $\begin{array}{l}6 \\
10(1), \\
20(2) ; \\
40(1) ; \\
160(2)\end{array}$ & 4,0 & $\begin{array}{l}5^{\#} \\
5(2) ; \\
10(3)\end{array}$ & 1,6 \\
\hline
\end{tabular}

Título (Log 2); GMT: título médio geométrico $(\log 2)$; n: número de animais por grupo; Nc* não calculado, somente um animal reagente; \# número de animais reagentes.

em três grupos (B, C e D) e, em todos os grupos, os títulos foram, em geral, inferiores aos observados contra o BoHV-1.

Com relação ao BVDV-1, apenas uma vacina $(G)$ induziu resposta sorológica detectável em todos os animais vacinados $(\mathrm{GMT}=6,7)$. Soroconversão parcial foi detectada em quatro grupos vacinais: H (6/10, GMT 4,0), B (6/10, GMT 5,6) e
E (4/10, GMT 1,8), sendo que a vacina A induziu resposta em apenas um animal e as vacinas $\mathrm{C}, \mathrm{D}$ e F não induziram anticorpos detectáveis contra $\mathrm{o}$ BVDV-1 em nenhum animal. Por outro lado, atividade neutralizante contra o BVDV-2 foi detectada apenas em animais vacinados com as vacinas $\mathrm{G}(100 \%$, GMT $6,5), \mathrm{H}(50 \%$, GMT 1,6) e B $(20 \%$, GMT 1,0). Cinco vacinas não induziram anticorpos com atividade 
neutralizante frente ao BVDV-2 em nenhum dos animais imunizados.

Em resumo, quatro vacinas não induziram resposta sorológica neutralizante frente ao BVDV-1 em nenhum animal e uma vacina induziu em apenas um animal (9\%). Cinco vacinas não induziram anticorpos frente ao BVDV-2 em nenhum animal, e uma induziu anticorpos em dois animais (20\%). Nenhum dos animais sentinelas soroconverteu aos vírus pesquisados no final do período experimental.

\section{DISCUSSÃO}

Os resultados obtidos demonstram situações distintas com relação aos agentes avaliados. Em geral, a resposta ao BoHV-1 foi consistente e em títulos aceitáveis $(\geq 8)$ na maioria das vacinas e animais. Mesmo que uma parcela considerável dos animais tenha desenvolvido títulos $<8$ - considerado referência para vacinas inativadas (US GOVERMENT PRINTING OFFICE, 2014) - a resposta desenvolvida pela grande maioria dos animais indica uma estimulação inicial adequada do sistema imunológico. A resposta de magnitude inferior e em parcela menor dos animais frente ao BoHV-5 era esperada, visto que apenas duas vacinas (A e D) contêm o BoHV-5 em sua formulação. Mesmo assim, grande parcela dos animais imunizados com as demais vacinas (que contêm apenas o BoHV-1) apresentou atividade neutralizante em níveis semelhantes frente ao BoHV-5. Por outro lado, a resposta sorológica induzida pela grande maioria das vacinas contra o BVDV, especialmente contra o BVDV-2, foi indetectável, situação que é inadequada, tanto do ponto de vista imunológico quanto do ponto de vista de controle e prevenção dessa infecção.

O BoHV-1 e BoHV-5 são antigenicamente muito próximos e apresentam uma extensiva reatividade sorológica cruzada, o que resulta em reação cruzada em testes de SN e em proteção cruzada in vivo (ANZILIERO et al., 2011). Por isso, a necessidade (ou não) de incluir os dois vírus em vacinas ainda é tema de debates. Se por um lado os dois vírus co-circulam no rebanho bovino brasileiro (SILVA et al., 2007), há uma corrente que acredita que bovinos imunizados adequadamente contra um desses agentes estariam protegidos contra o vírus heterólogo (DEL MÉDICO ZAJAC et al., 2006; Flores, comunicação pessoal). Se este for o caso, a presença apenas do BoHV-1 nas vacinas (como ocorre atualmente na maioria delas) seria suficiente para a produção de proteção contra ambos. Dados de campo ainda são necessários para comprovar essa hipótese, mas vários experimentos já realizados são compatíveis com níveis aceitáveis de proteção cruzada (DEL MÉDICO ZAJAC et al., 2006; ANZILIERO et al., 2011).

No Brasil, não existe uma regulamentação específica definindo o nível de imunidade exigido para vacinas contra esses vírus. No entanto, considerando-se referências/regulamentações de outros países, vacinas inativadas e/ou atenuadas contra o BoHV-1 deveriam induzir títulos neutralizantes $\geq 8$ e pelo menos $80 \%$ de animais reagentes (US GOVERMENT PRINTING OFFICE, 2014). Nesse sentido, o grupo "G” (Tabela 1; vacina viva atenuada) foi o que apresentou os melhores resultados, seguido dos grupos "H" (vacina viva atenuada), e das vacinas inativadas "E", "A", "F", "B", "D" e "C". A maior imunogenicidade das vacinas $\mathrm{G}$ e $\mathrm{H}$ devem-se, sobretudo, ao fato de conterem vírus atenuados, cuja resposta é de magnitude geralmente maior do que vacinas inativadas (MEEUSEN et al., 2007). É interessante ressaltar que o título mínimo de $\geq 8$ refere-se principalmente a vacinas inativadas, pois o perfil de resposta imunológica induzido por vacinas atenuadas é mais complexo e não pode ser avaliado exclusivamente pelos níveis de anticorpos (ANZILIERO et al., 2011).

Em se tratando do BVDV, a biologia do vírus e a resposta imunológica do hospedeiro parecem ser ainda mais complexas. A grande variabilidade antigênica do vírus (RIDPATH et al., 1994) e a existência de dois tipos antigênicos distintos (BVDV-1 e BVDV-2), cuja reatividade sorológica cruzada é baixa (RIDPATH et al., 1994; BIANCHI et al., 2011), são obstáculos para o sucesso da vacinação. No Brasil, as vacinas comerciais contra o BVDV contêm apenas suspensões virais inativadas, sendo que a maioria delas contém o BVDV-1 e BVDV-2 (MAPA, 2013). Dentre os oito imunobiológicos avaliados, somente cinco (grupos “A”, "B”, "E”, "G” e "H”) induziram resposta detectável frente ao BVDV-1 e, mesmo assim, dois deles em uma parcela pequena dos animais $(A=1 / 10 ; E=4 / 10)$ e outros dois em $60 \%$ dos animais (B e H). De fato, a vacina " $G$ " foi a única que induziu resposta consistente (100\% dos animais) e em títulos moderados a altos (tanto para o BVDV-1 quanto para o BVDV-2). Nessa vacina, em particular, é provável que o adjuvante utilizado tenha sido o diferencial na boa indução de resposta aos antígenos inativados do BVDV.

A resposta frente ao BVDV-2 foi ainda mais inconsistente e preocupante: apenas a vacina $\mathrm{G}$ induziu resposta em todos os animais e, novamente, em títulos moderados a altos e, provavelmente suficientes para conferir proteção (US GOVERMENT PRINTING OFFICE, 2014). A vacina $H$ induziu anticorpos em 
títulos baixos em $50 \%$ dos animais e a vacina B induziu títulos mínimos detectáveis em apenas dois animais. De forma preocupante, cinco vacinas não induziram atividade neutralizante detectável frente ao BVDV-2 em nenhum animal vacinado. Considerandose que tanto o BVDV-1 quanto o BVDV-2 circulam no rebanho bovino brasileiro (FLORES et al., 2000), a grande maioria dessas vacinas, se utilizadas nos protocolos e condições do presente experimento, seria inócua para conferir proteção frente a esses vírus.

\section{CONCLUSÃO}

Os resultados obtidos nas condições do presente experimento permitem concluir que a imunogenicidade do BoHV-1 da maioria das vacinas comerciais é aceitável e, provavelmente, suficiente para uma imunização adequada dos rebanhos, desde que seguidas as recomendações dos fabricantes. A imunogenicidade do componente BVDV-1 foi indetectável em pelo menos quatro vacinas e, do BVDV-2, em pelo menos seis vacinas. Fica evidente que as estratégias de formulação e/ou produção de vacinas, principalmente com relação ao BVDV, devem ser urgentemente revistas.

\section{COMITÊ DE ÉTICA}

O projeto foi submetido ao Comitê de Ética e Bemestar Animal, Universidade Federal de Santa Maria (UFSM), e aprovado sob o parecer 096/2010.

\section{AGRADECIMENTOS}

Ao Conselho Nacional de Desenvolvimento Científico e Tecnológico (CNPq) e à Coordenação de Aperfeiçoamento de Pessoal de Nível Superior (Capes) pelo fornecimento de recursos e bolsas, contribuindo de maneira essencial para o desenvolvimento da pesquisa.

\section{REFERÊNCIAS}

ACKERMANN, M.; ENGELS, M. Pro and contra IBR-eradication Veterinary Microbiology, Amsterdan, v.113, p.293-302, 2006. Disponível em: <http://www.sciencedirect.com/science/article/pii/ S0378113505003780>. Acesso em: 12 jan. 2013. doi: 10.1016/j. vetmic.2005.11.043.

ANZILIERO, D. et al. A recombinant bovine herpesvirus 5 defective in thymidine kinase and glycoprotein $\mathrm{E}$ is immunogenic for calves and confers protection upon homologous challenge and BoHV-1 challenge. Veterinary Microbiology, Amsterdan, v. 154, p.14-22, 2011. Disponível em: <http://www.sciencedirect.com/ science/article/pii/S037811351100174X >. Acesso em: $12 \mathrm{jan}$. 2014. doi: 10.1016/j.vetmic.2011.03.019.

BAUERMANN, F. et al. HoBi-like viroses: an emerging group of pestivirus. Journal of Veterinary Diagnostic Investigation,
Columbia, v.25, n.1, p.6-15, 2013. Disponível em: <http://vdi. sagepub.com/content/25/1/6.full>. Acesso em: 6 jan. 2013. doi: $10.1177 / 1040638712473103$.

BIANCHI, E. et al. Perfil genotípico e antigênico de amostras do vírus da diarréia viral bovina isoladas no Rio Grande do Sul (20002010). Pesquisa Veterinária Brasileira, Rio de Janeiro, v.31, p.649-655, 2011. Disponível em: <http://www.scielo.br/pdf/pvb/ v31n8/a03v31n8.pdf> Acesso em: 15 jan. 2013. doi: 10.1590/ S0100-736X2011000800003.

DEL MÉDICO ZAJAC, M. et al. BHV-1 vaccine induces cross-protection against BHV-5 disease in cattle. Research in Veterinary Science, England, v.81, p.327-334, 2006. Disponível em: 〈http://www.ncbi.nlm.nih.gov/pubmed/16540133>. Acesso em: 23 jan. 2013. doi: 10.1016/j.rvsc.2006.01.004.

ENGELS, M.; ACHERMANN, M. Pathogenesis of ruminant herpesvirus infections. Veterinary Microbiology, Amsterdan, v.54, p.3-15, 1996. Disponivel em: <http://www.sciencedirect. com/science/article/pii/S0378113596012308>. Acesso em: 12 jan. 2013. doi: 10.1016/S0378-1135(96)01230-8.

FLORES, E.F. et al. Clinical, pathological and antigenic aspects of bovine viral diarrhea virus (BVDV) type 2 isolates identified in Brazil. Veterinary Microbiology, Amsterdan, v.77, p.175-183, 2000. Disponível em: <http://www.sciencedirect.com/science/ article/pii/S0378113500002741>. Acesso em: 7 jan. 2013. doi: http://dx.doi.org/10.1016/S0378-1135(00)00274-1.

MAPA. Coordenação de fiscalização de produtos veterinários relatório de produtos com licença vigente $05 / 2013$. Disponível em: <http://www.agricultura.gov.br/animal/produtosveterinarios>. Acesso em: 12 set. 2013.

MEEUSEN, E.N.T. et al. Current status of veterinary vaccines. Clinical Microbiological reviews, United States. v.20, p.489510, 2007. Disponível em: <http://www.ncbi.nlm.nih.gov/pmc/ articles/PMC1932753/> . Acesso em: 23 jan. 2014. doi:10.1128/ CMR.00005-07.

OIE. Manual of diagnostic test and vacines for terrestrial animal 2013. v.1, section 2.4 , chapter 2.4 .8 and 2.2.13. Disponível em: <http://www.oie.int/international-standard-setting/terrestrialmanual/access-online/>. Acesso em: 20 out. 2013.

RIDPATH, J.F. et al. Segregation of bovine viral diarrea vírus into genotypes. Virology, New York, v.205, p.66-74, 1994. Disponível em: <http://www.sciencedirect.com/science/article/ pii/S0042682284716205>. Acesso em: 9 jan. 2013. doi: 10.1006/ viro.1994.1620 .

SILVA, M.S.I et al. Molecular and antigenic characterization of Brazilian bovine herpesvirus type 1 isolates recovered from the brain of cattle with neurological disease. Virus Research (Print), Amsterdan, v.129, p. 191-199, 2007. Disponível em: <http:// www.sciencedirect.com/science/article/pii/S0168170207002766>. Acesso em: 7 jan. 2013. doi: http://dx.doi.org/10.1016/j. virusres.2007.07.014.

US GOVERMENT PRINTING OFFICE. Code of Federal Regulations, Animal and animal products. 9 CRF 113.215 - Bovine virus diarrhoea vaccine, killed virus. v.1, chapter I, subchapter E, part 113, section 113.215/216. Disponível em: <http://www.gpo.gov/fdsys/pkg/CFR-2012-title9-vol1/xml/CFR2012-title9-vol1sec113-215.xml>. Acesso em: 21 jan, 2013. 